\title{
AS BASES CONSTITUTIVAS DO PROCESSO DIVISIONISTA DO ESTADO DO PIAUÍ
}

\author{
Wendell Teles de Lima ${ }^{1}$ \\ Cleuter Tenazor Tananta ${ }^{2}$ \\ Ana Maria Libório de Oliveira ${ }^{3}$
}

\begin{abstract}
Resumo
O processo de redivisão atual do Estado do Piauí leva a proposição de criação ao sul do estado, contextualizado o fenômeno, observou-se o surgimento de uma nova unidade interiorizada no território brasileiro. Fruto da expansão econômica e do estabelecimento de atores territorializantes. E suas ações devem ser analisadas de forma relativizada com a atualidade. Correlações são necessárias para entender que os processos divisionistas não são aleatórias, o surgimento da Gurgueia é ligado a esse fenômeno. Para sua compreensão foi desenvolvida uma pesquisa bibliográfica, baseada na compressão das propostas divisionistas, que têm relação com a modificação piauiense, que visa analisar e identificar as propostas direcionadas ao Piauí com objetivo de aprofundar a proposta de divisão atual.
\end{abstract}

Palavras-chaves: Piauí; Divisão; Propostas.

\section{THE BASES CONSTITUTIVE PROCESS OF DIVISIVE PIAUÍ STATE}

\begin{abstract}
The current redivision process of Piaui State takes the proposition creation south of the state, contextualized the phenomenon, there was the emergence of a new internalized unit in Brazil, the result of economic expansion and the establishment of territorializantes actors, their actions They must be analyzed in context with the present form. Correlations are needed to understand that divisive processes are not random, the emergence of Gurgueia is attached to this phenomenon, for their understanding has developed a literature search, based on understanding of divisive proposals, which relate to the Piauí modification, which aims to analyze and identify the proposals directed to the Piauí in order to deepen the proposed current division.
\end{abstract}

Keywords: Piauí; Division; Proposals.

\footnotetext{
${ }^{1}$ Doutor em Geografia, Professor do Centro de Estudos Superiores de Tabatinga (CSTB) da Universidade do Estado do Amazonas (UEA). Email: wendelltelesdelima@gmail.com

${ }^{2}$ Mestre em Educação, Professor do Centro de Estudos Superiores de Tabatinga (CSTB) da Universidade do Estado do Amazonas (UEA). Email: ctenazor1@gmail.com

${ }^{3}$ Mestre em Natureza e Cultura da Amazônia, Professora do Instituto Federal do Paraná (IFPR) - Campos Foz do Iguaçu. Email: analiborio@gmail.com
}

Sociedade e Território - Natal. Vol. 28, N. 1, p. 137-155. Jan./Jun. de 2016 


\section{LE PROCESSUS BASES DE CONSTITUTIF DIVISION ÉTAT PIAUÍ}

\section{Résumé}

Le processus de redécoupage actuel de Piaui État prend la création de proposition au sud de l'état, en contexte le phénomène, il a été l'émergence d'une nouvelle unité intériorisé au Brésil , le résultat de l'expansion économique et la création d' territorializantes acteurs, leurs actions ils doivent être analysées dans le contexte de la forme actuelle. Les corrélations sont nécessaires pour comprendre que les processus de division ne sont pas aléatoires, l'émergence de Gurgueia est attaché à ce phénomène , pour leur compréhension a développé une recherche documentaire, basée sur la compréhension des propositions controversées, qui ont trait à la modification Piauí , qui vise à analyser et d'identifier les propositions adressées au Piauí afin d'approfondir la division actuelle proposée .

Mots-clés: Piauí; Division; Propositions.

\section{INTRODUÇÃO}

O objetivo do trabalho é compreender o processo de redivisão do Estado de Piauí ao longo da história. Tem-se como relação e reflexão a constituição da proposição do estado da Gurgueia. A justificativa é aprofundar de forma acadêmica a análise geográfica sobre, as questões divisionistas que permeiam à sociedade brasileira atual, a metodologia tem um cunho qualitativo baseada em pesquisa bibliográfica.

$\mathrm{Na}$ disposição das ideias e análises têm-se no primeiro ponto, o aprofundamento e apreciação para identificação das propostas divisionistas. Destaca-se o caso do Piauí, portanto, são contextualizadas apenas as propostas que têm relação com esse estado. A proposta de discussão atual, que ocorre em torno da criação do Estado da Gurgueia, citado seus elementos favoráveis e desfavoráveis na possível criação, finalizado com resultados de reflexões.

\section{COMPREENDER O PROCESSO DE FORMAÇÃO DO PODER NA FORMAÇÃO TERRITORIAL}

O processo de divisão territorial do Brasil é parte integrante da constituição do próprio território, de divisão administrativa do país ocorreu com a criação das Capitanias Hereditárias, instituídas por D. João III, em 1534, vigorado até 1759. Com objetivo de colonizar, proteger e administrar o território. As obrigações insidiam diretamente na exploração de cada capitania como a necessidade de proteção contra possíveis invasões. $\mathrm{O}$ estímulo à atividade econômica e povoamento, a obediência ao poder real, dessa forma, trata-se do poder real vigente no país. 
As relações institucionais ou relações entre Estados, Municípios e União podem ter como parte constituinte de seu cerne atual a organização política baseada na própria divisão, refletido na constituição dos poderes essenciais para a manutenção e ao mesmo tempo, contribuir para o reconhecimento do poder colonial, que deveria ser regido pelas trocas políticas e econômicas. Onde concretizavam na divisão do territorial com a criação das capitanias e comarcas.

Outro processo ligado e usado para a consolidação e controle do território é originado pela expansão das atividades econômicas em direção ao seu interior. A área territorial retratada corresponde a uma estreita faixa de terra, que se estendia de Belém a Cidade de Laguna, no Estado de Santa Catarina. E o restante do território estava sobre o domínio da Coroa Espanhola.

As atividades econômicas que deram origens algumas funcionalidades territoriais, onde repercutem no novo processo de divisão e o surgimento de novas povoações em função da necessidade da atividade pecuarista extensivas. No resultado final da instituição desse regime territorial foi criada em 1758, a Capitania do Piaú com a capital na Cidade de Oeiras. O avanço em direção ao interior pela criação de gado ocorreu em função da proibição no litoral de atividade; de plantação da cana de açúcar, somada a doação das sesmarias constituem parte integrante para o estímulo do surgimento do Piauí, dá origem a nova capital e circunscrição interiorizada. Egler (1952) observa que em 1940, Teresina e Parnaíba despontam como as principais cidades do estado, refletidos sobre a capital alguns fatores, são colocados suas elevações como partes integrantes ferroviária do Maranhão, a importância de sua posição na Bacia do Rio Parnaíba, portanto, ultrapassada sua importância comparada a Oeiras,

Teresina e Parnaíba são os mais importantes centros urbanos do estado. A primeira conta com 34.695 habitantes. É hoje a capital, em substituição à antiga e decadente cidade de Oeiras. Graças à sua situação como ponta de trilhos da Estrada de Ferro São Luís - Teresina e ainda e beneficiada pela navegação regular do Parnaíba é atualmente o maior entreposto comercial de toda a região e do estado. Sua esfera de influência se faz sentir em todo Piauí por ser a receptora dos produtos do interior e o principal centro exportador. Tem comércio bem desenvolvido e uma feira semanal onde se reúnem forasteiros vindos de todos os recantos. Tem também algum movimento industrial, com fábricas de tecidos, de fumo, de óleos vegetais e máquinas de beneficiamento de arroz, algodão e engenhos de cana-de-açúcar, ale de laticínios e charqueadas. (EGLER, 1952, p. 490). 
O papel político da Cidade de Teresina é parte integrante de uma nova lógica territorial, resultante do avanço dos transportes, ainda no que tange as relações de poder estabelecidas em torno da constituição de uma nova capital. Tem à mudança de regime governamental do país e o seguinte quadro, as relações de províncias ao norte intensas com Portugal. O restante do país, fato esse relacionado à aproximação com as metrópoles européias. Entretanto, relações tênues enfraqueciam a coesão territorial, movimento ocorrido a favor da expulsão dos portugueses, da Monarquia necessariamente não trouxe estabilidade política ao país. Magnoli (2003) analisa a relação entre as províncias e o Império

O Estado imperial construiu-se como argamassa de uma entidade oligárquica de tipo pré-nacional. O centro político, materializado no imperador e no Conselho de Estado, teria de funcionar como gestor dos múltiplos e eventualmente conflitantes interesses das oligarquias dominantes, que se expressavam de modo desigual no vasto território brasileiro. A fragilidade do conjunto residia na sua precária coesão, principalmente em razão da fratura de descontinuidade social representada pela instituição da escravidão. A escravidão era, contudo, o alicerce social a ser preservado pelo Estado. Paradoxalmente, o sucesso histórico do Império derivou dessa fonte original de fraqueza que, funcionando como pólo aglutinador dos interesses essenciais das oligarquias, possibilitou a concentração do poder político. (MAGNOLI, 2003, p. 2).

As revoltas separatistas retratam a insatisfação popular e comercial e, são exemplos como a dos comerciantes em algumas províncias, que resultam em combates e insatisfação, diante das lutas estabelecidas, têm-se a Confederação do Equador e, contrapunha-se a identidade abaixo discutida na independência, conforme Martins (2001),

Desde a época da Independência, na fase de organização do Estado e ao longo do período Imperial, as elites políticas enfrentaram o problema do separatismo. São recorrentes, na historiografia brasileira, observações sobre o estado de desagregação das províncias e a preocupação das elites com a questão da unidade política e territorial. Abreu (1982), na conclusão de seus Capítulos de História Colonial, acentuou as diferenças regionais que agiam na hora da independência. Oliveira Vianna (1933, p. 274-282) disse que a unidade não fora um feito, mas um lento processo histórico, e realçou as tendências discordantes que separavam as províncias nas vésperas e durante o processo da independência. Nas palavras desse importante intérprete do Brasil: Proclamada a independência da colônia, o pensamento dos homens, a que ia caber a formidável incumbência de organizar o governo nacional, já não podia ser o outro: a necessidade de manter a unidade política do país toma o primeiro lugar no plano das suas cogitações construtoras. Eles não têm diante de si uma vasta colônia a explorar (...) mas, uma pátria a organizar, uma nação a construir, um povo a governar e dirigir (...) um povo esfacelado em quase vinte partes autônomas, com pequeníssimas, se não nulas, relações de interdependência (...) o sentimento de uma pátria única não está ainda formado: as várias capitanias, que vão ser as futuras províncias, não se sentem membros de uma mesma família. (MARTINS, 2001, p. 264 -265) 
O processo emancipatório era em torno da discussão do absolutismo e, forma do governo centralizado, repercutido nas revoltadas, como a Confederação do Equador, que se impunham as ideias homogeneizadoras de independência, de forma autoritária diminuiu o poder das províncias. A constituição do poder no Brasil, as relações entre Poder Geral e Províncias substituídas pelo surgimento da União e dos Estados tendem a ser contraditória, em que muitas vezes, ao longo do período histórico, ocorre choques entre duas concepções políticas, uma baseada no centralismo, no poder sobreposto aos Estados pela União e outro pela maior autonomia dos entes federados.

Na constituição de uma visão interna baseada no fortalecimento da união e, ao mesmo tempo, somada ao aumento do poder das oligarquias regionais e extrarregionais, e interesses difusos repercutem e fomentam o processo de criação de novos estados, isso retrata a complexidade do jogo político, onde se consolida com a constituição de novas unidades federadas.

\section{O PIAUÍ AO LONGO DAS PROPOSIÇÕES DIVISIONISTAS}

Analisada a proposta de criação de novas circunscrições no país, ao longo da história, são demonstradas algumas particularidades de seus propositores, como a de Fausto de Souza de 1880, no Século XIX, propõe a divisão do país em 40 províncias e, tem como característica a manutenção de pequenas áreas territoriais, aumento da extensão de algumas províncias e diminuição, ao mesmo tempo, das grandes áreas territoriais, outro mecanismo utilizado é a anexação de áreas territoriais oriundas de uma única província ou pela junção de mais de uma unidade. As Províncias de: Piauí e Maranhão, através do processo de desanexá-los para anexá-los em áreas conjuntas, daria origem à Província do Urucu, conforme aponta Grande (1965).

Mal se reconhece as atuais unidades federadas na divisão territorial, proposta por Fausto de Souza em 1880, em quarenta províncias, na qual percebe a tendência de conservar as áreas de pequenas unidades como: Rio de Janeiro, Espírito Santo, Paraíba, Rio Grande do Norte, e mesmo, ampliá-las (Alagoas, Sergipe, Pernambuco). Porém reduzir as superfícies de unidades maiores, como Bahia, cujo território atual, seria as seguintes cidades: Ilhéus, Porto Seguro, São Francisco; o Maranhão perderia o Turi-Açu e, ajudaria o Piauí a formar a Província de Uruçuí: o Pará, reduzido à área relativamente pequena, cederia superfícies. (GRANDE, 1965, p.626). 
A área que representaria essa província correspondia ao norte do Maranhão e Piauí, que nesse momento era motivo de preocupações, em virtude de sua baixa densidade demográfica e, ao mesmo tempo, seu isolamento, ou seja, falta de conexão com a cidade de Oeiras. Ocorreu que muitas províncias, que não conseguiram seu processo de emancipação, em virtude do peso político das oligarquias regionais, o estabelecimento de novo poder, que poderia disputar ou diminuir a influência política desses grupos. Numa análise baseada em uma escala geográfica macro, tem como componente o Império, dá-se a seguinte característica, o desinteresse aparente do Governo Geral na criação de novas unidades, embasado no mito da integridade territorial como demonstra Castro (1997).

\begin{abstract}
No momento da independência o território brasileiro era um desenho no mapa, não havia fronteiras definidas por acordos internacionais que garantissem a soberania sobre o território. No entanto, em nome dessa unidade territorial todos os movimentos de caráter regional eram sufocados, mesmo os que não tinham reivindicações separatistas: no período colonial, em nome da integridade do Império; após a independência, para preservar o mito fundador da herança territorial. Assim, a identidade nacional fundada na extensão territorial, que estabelecia a legitimidade da fé no destino de grande potência, e a unidade lingüística e religiosa, que fornecia as bases da legitimidade da integração territorial, tomava qualquer diferença entre brasileiros de diferentes áreas do imenso território um tema para estudos sobre o folclore, e dificilmente uma questão que pudesse ter qualquer conteúdo analítico mais conseqüente. A unidade territorial e social constitui, pois, para muitos ideólogos do Estado brasileiro, a base necessária da coesão social garantida pela adesão ao pacto da nacionalidade. (CASTRO, 1997, p. 35).
\end{abstract}

O processo de controle do território é compartilhado com o pacto político estabelecido pelos interesses das oligarquias regionais e, ao mesmo tempo, com o Governo Geral, portanto, tem-se o número de estabelecimentos de províncias existentes, em virtude do próprio pacto político constituído pelos interesses do Governo Geral e Oligarquias.

O período de transição entre República Velha (1889 - 1930) e República Nova (1930 1985) trouxe algumas questões à respeito do sistema político do país, que estava diretamente ligado à própria forma interna como foi constituído, ou seja, o modelo adotado que era inapropriado baseado no federalismo, era inadequado para realidade do país, como não estava ligada a sua tradição histórica.

A quebra hegemônica da República Café com Leite (1894 e 1930) e o próprio relativo enfraquecimento oligárquico representa uma nova forma de organizar e pensar o país, que é baseada no industrialismo e, por sua vez, maior participação dos Estados que devem ser relativizadas. Entretanto, algumas propostas de cunho moderno conservador estão presentes 
nas propostas de divisão, que ressoam nos anos de 1930, adiante como do geopolítico Everardo Backheuser.

As ideias Backheuser centravam-se na forma de adoção da política baseada na República e no Federalismo, tem como consequências, a problemática da fragmentação do território e o fortalecimento regional, esse geopolítico o sistema de governo ideal para o Brasil seria o Império, forma de governo inicial adotada em sua formação. $\mathrm{Na}$ adoção de diminuir a influência das forças internas, tem-se a constituição de uma nova divisão territorial, onde o equilíbrio ocorreria pelo formato proposto através de linhas constituídas por paralelos e meridianos (Figura 01). Portanto, não leva em consideração as tradições históricas, regionalismos e limites naturais, assim, equilibrado o poder das unidades administrativas e aumento o poder de coesão territorial.

Figura 01: Proposta de Everardo Backheuser 1933.

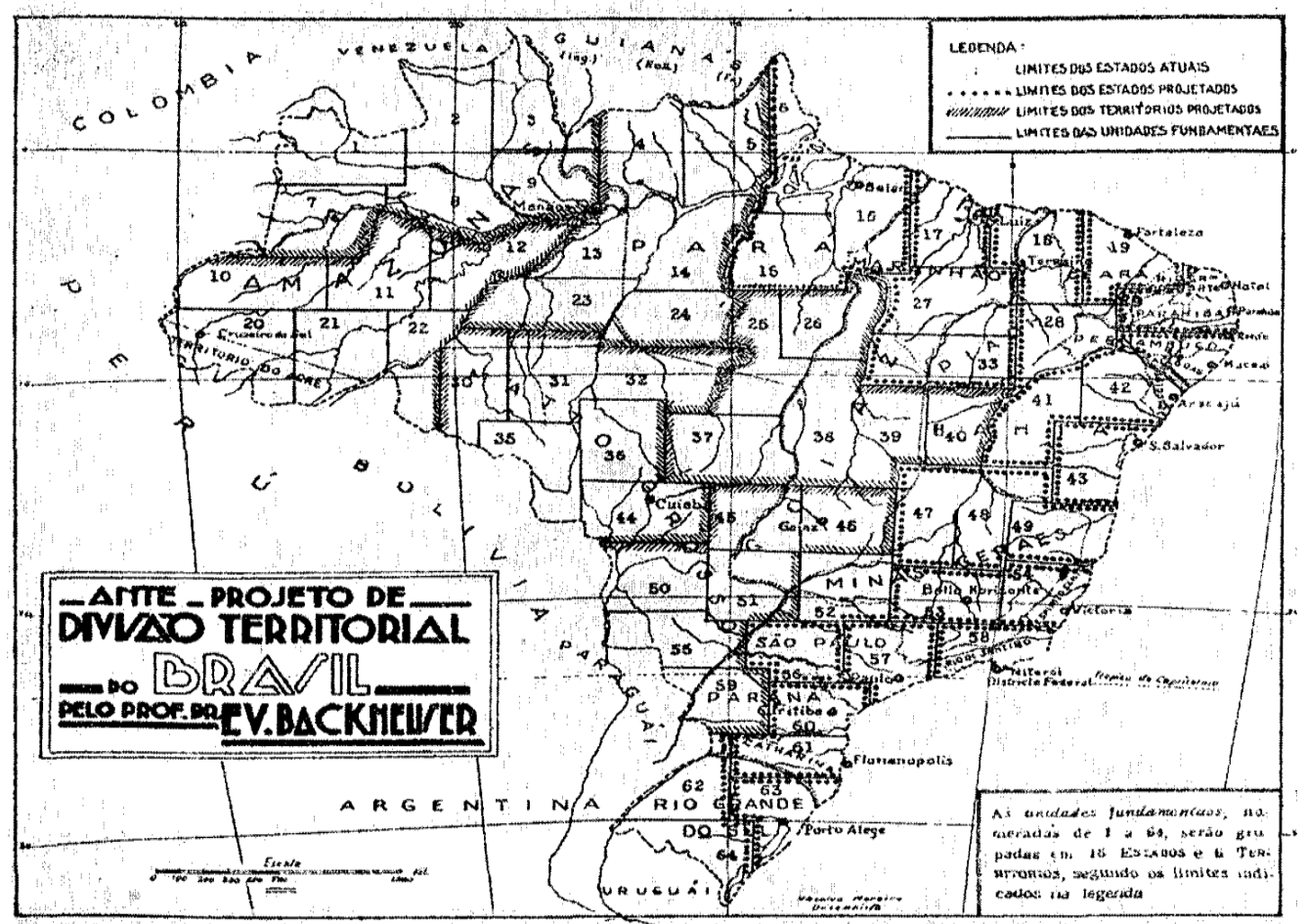

Fonte: Thiers Fleming Revista Brasileira de Geografia 1940.

Essa denominação é dada por Backheuser como equipotência territorial, em que é levada em consideração a área territorial e o tamanho da população, distribuído de forma proporcional em todo o território brasileiro. O formato interno do país, ou seja, a forma dos Estados teria a mesma semelhança da divisão política dos Estados Unidos, ou seja, um 
formato retangular, e assim, reforça a ideia de não respeitar as tradições históricas, o que poderia fortalecer o poder das oligarquias regionais.

Assim, tem como resultado do projeto de Backheuser, nesse sentido, de 64 unidades e uma área territorial, que deveria ser de 120 mil quilômetros quadrados, como mostra Nogueira (2007),

\begin{abstract}
Sua proposta, então, para redesenhar o mapa interno do Brasil, tomava por base o "principio cientifico da equipotência", cujos fatores básicos estavam constituídos pela superfície - espaço, no sentido de área, e situação, frente às coordenadas e aos acidentes físicos; população - considerando a densidade; e a economia - do presente e futuro.

As unidades territoriais deveriam, deste modo, ter uma extensão territorial mínima de 100 mil Km² e no máximo de 300 mil Km², sendo seu formato um retângulo, e seus limites seriam definidos pelas linhas imaginarias, pois estas "são imparciais, não favorecem ninguém". Quanto à população, Backeheuser pensava em estipular um número próximo de um milhão como mínimo. O problema deste fator era não só seu crescimento como seu movimento. Já a equipotência econômica estaria relacionada à população afirmando que as zonas mais ricas serão as mais populosas. Admitia a existência transitória dos territórios federais, cuja extensão poderia ser até seis vezes maiores que a unidade mínima dos Estados. Resumindo, sua divisão daria ao Brasil 16 Estados em 28 unidades fundamentais e 6 territórios em 36 unidades fundamentais, totalizando 64 unidades. (NOGUEIRA, 2007, p, 68).
\end{abstract}

O Estado do Piauí (Figura 1) aparece subdividido em duas porções, a que está o Maranhão, é uma pequena parte leste desse estado, aumenta o litoral piauiense, somado a uma pequena parte do litoral do oeste do Ceará, parte oeste de Pernambuco e uma pequena porção do noroeste da Bahia. A outra porção (Figura 1), que não seria possível denominar em função do geopolítico e parte sul do estado, que com a parte central do Maranhão e seu sul somado a boa parte leste do atual Tocantins. Assim, constituiria uma nova unidade administrativa, essa porção corresponde hoje à região de grande produção de grãos desses estados.

$\mathrm{Na}$ sintetização das ideias do geopolítico, Everardo Backheuser, observa-se sua fonte de inspiração baseadas nas ideias ratzelianas e nas diretrizes tomadas, e seguidas pelo geógrafo e geopolítico Kjjelén, como observado pelo próprio Backheuser na exposição do conceito de geopolítica conforme as ideias baseadas no geógrafo sueco,

O segundo ramo da política é demopolítica (ou etnopolítica) o qual estuda o povo e
as raças não como o faria a etnografia, mas nas suas relações políticas como nação.
Fazendo como que uma ligação deste ramo como o primeiro, a política tem um
terceiro campo de investigações - a exploração do país pela nação para o
desenvolvimento da autarquia econômica. Este3 terceiro ramo da política tem um
terceiro campo de investigações - a exploração do país pela nação para o
desenvolvimento da autarquia econômica. Este terceiro ramo da política Kjellén o
denominou de ecopolítica e nós o chamamos autarcopolítica. Não é ele a economia
política nem a geografia econômica, embora mais próximo desta. O estudo da 
sociedade, dentro da nação, é objeto da sociopolítica (o Dr. Ramiz Galvão a que consultamos sugeriu o vocábulo cenopolítica, lingüisticamente mais homogêneo). Como quinto e ultimo ramo de estudo, o autor escandinavo compendia os assuntos que diretamente se referem às questões de governo e administração, ou seja, ao regime político e às manifestações da soberania e que vulgarmente são considerados como os únicos ou os principais objetos de política: é a cratopolítica de Kjellén. (BACKHEUSER, 1942, p.24).

No período denominado ainda de República Nova, observa-se várias propostas em torno da divisão territorial, como do major Segadas Viana, em 1933, que propunha a criação de estados e territórios federais, teve em vista a área territorial mais ou menos equivalente a todas as unidades e, como a prevalência de limites, os rios, em sua proposta, o país seria organizado da seguinte forma: um Distrito Federal, vinte e sete Estados e trinta e nove Territórios Federais . Portanto, o Brasil seria composto de sessenta e sete unidades.

Em sua proposta, observa-se o surgimento de territórios federais na região nordeste, como o Gurgueia, que é reivindicado nos dias atuais, tem como meta o investimento nessas áreas pela União, para Viana (1940), a divisão levaria em consideração três princípios: o desenvolvimento de áreas pela criação de territórios, divisão equilibrada das extensões e dos grandes estados e, distribuição populacional equilibrada entre os grandes estados populosos.

No primeiro princípio, tem-se a constituição dos territórios federais, que os mesmos podem ser elevados à categoria de estados com o passar do tempo, como visto.

\footnotetext{
1. - fixar um limite mínimo de população para que um determinado território possa a ter a categoria de Estado (200.000 hbs. por ex.), sem o que ficará como simples território subordinado diretamente e dirigido pela União, que promoverá o seu desenvolvimento com muito mais recursos. Duas únicas exceções abriram em nosso trabalho; são os territórios onde ficarão as antigas capitais de Mato Grosso e Amazonas, que ficarão autônomos, como Estados, a fim de manter uma tradição histórica que em nada prejudica a solução em seu conjunto. (VIANA, 1940, p.384).
}

Em sua proposta, as únicas exceções de forma de organização baseada na constituição de formação em Território Federal são: Mato Grosso e Amazonas, que passariam a ser denominados por essa categoria e, ao mesmo tempo, teriam certa autonomia em relação aos demais, em função, de acordo com o propositor de sua própria tradição histórica, ou seja, pela existência anterior aos demais. 
No ano de 1941, tem-se a proposta de Teixeira de Freitas, como projeto a redivisão brasileira em 16 estados e 13 territórios conforme visto abaixo (tabela 01) ${ }^{4}$

Tabela 01: Redivisão Política do Brasil.

\begin{tabular}{l|l}
\hline \multicolumn{2}{c}{ Divisão Proposta de Teixeira de Freitas } \\
\hline Unidades Administrativas & Capitais \\
\hline Acre (Estado) & Rio Branco \\
\hline Amazonas (Estado) & Manaus \\
\hline Araguaia (Território) & Carajás \\
\hline Araguari (Território Federal) & Macapá \\
\hline Baía (Estado) & Salvador \\
\hline Borborema (Estado) & Ico \\
\hline Dist. Federal & Belo Horizonte \\
\hline Goiás (Estado) & Goiânia \\
\hline Guaporé (Território Federal) & Cáceres \\
\hline Iguaçu (Estado) & União da Vitória \\
\hline Madeira (Território Federal) & Borba \\
\hline Mamoré (Território Federal) & Santo Antônio \\
\hline Mantiqueira (Estado) & Guanabara \\
\hline Maranhão (Estado) & São Luiz \\
\hline Mato Grosso (Estado) & Cuiabá \\
\hline Minas Gerais (Estado) & Patrocínio \\
\hline Mucuruí (Estado) & Teófilo Otoni \\
\hline Pará (Estado) & Belém \\
\hline Piauí (Estado) & Teresina \\
\hline Purus (Território Federal) & Tefé \\
\hline Rio Grande do Sul (Estado) & Porto Alegre \\
\hline Rio Negro (Território Federal) & São Gabriel \\
\hline Rio Pardo (Território Federal) & Campo Grande \\
\hline São Francisco (Estado) & Paulo Afonso \\
\hline São Paulo (Estado) & São Paulo \\
\hline Solimões (Território Federal) & São Paulo de Olivença \\
\hline Tapajós (Território Federal) & Santarém \\
\hline Tocantins (Território Federal) & Pedro Afonso \\
\hline Tumucumaque (Território Federal) & Óbidos \\
\hline Xingu (Território Federal) & Altamira \\
\hline & \\
\hline
\end{tabular}

Fonte: Teixeira de Freitas adaptado pelo autor.

A presença de territórios federais é freqüente, como a divisão de vários estados, outra mudança importante sugerida, é a localização da Capital Federal, em Belo Horizonte, para Freitas (1941), algumas modificações poderiam ser corrigidas com a redivisão, neste caso, a

\footnotetext{
${ }^{4}$ Os nomes dos Estados e Territórios Federais foram grafados de acordo com a escrita do texto retirado de Teixeira de Freitas de 1941.
} 
diminuição das grandes extensões territórios dos estados, o avanço do desenvolvimento em direção ao oeste, pela criação de novas unidades e o aumento das áreas territoriais dos pequenos estados existentes, conforme visto,

\begin{abstract}
Obra de equidade para com os pequenos Estados, que tão desigualmente tem sido tratado pela Federação; obra de justiça para com as abandonadas populações interiores dos Estados territorialmente grandes, que são também, paradoxalmente, os mais pobres, e com isso se vêem obrigados a deixar, não só em abandono àquelas populações, mas perigosamente desocupada e inexplorada a maior e melhor parte do território nacional; obra de "são política", porque, assim, bem "filha da moral e da razão"; obra de mise em valeur, em beneficio do Brasil, do maior potencial ferrífero do mundo; obra de resguardo da metrópole brasileira; obra de interiorização salutar forças de progresso; obra de engrandecimento e desdobramento da missão das nossas gloriosas forças armadas, missão que, já agora, seria também a de preparar e realizar a incorporação do Brasil ocidental à vida efetiva da Nação; obra de salvação nacional, numa palavra, - eis o que seria assim compreendida, a reestruturação energética e viril, ao mesmo tempo em que prudente hábil e transigente, do Quadro Maior da Organização Política do Brasil. (FREITAS, 1941, p.538).
\end{abstract}

O Estado do Piauí surge complementado, como área de extensão territorial marítima do Maranhão, portanto, desperta a curiosidade, pois em algumas propostas de divisão territorial, este fato permanece como as ideias de Freitas de 1941, as áreas territoriais desse estado são equivalentes ao Maranhão, porém, há uma preocupação nesse sentido pelo propositor, com relação às demais unidades. Borberema, como nova unidade, teria parte integrante o Ceará, Rio Grande do Norte, Paraíba, São Francisco e seria constituído por: Pernambuco, Alagoas, Sergipe e boa parte do norte da Bahia, essas seriam as modificações feitas no Nordeste com a manutenção do estado baiano e sua diminuição da área territorial.

No decorrer do desenvolvimento de proposições para o país, tem-se a priorização da integridade do território. A proposta do geógrafo, Antônio Teixeira Guerra, em 1948, criaria um grande número de territórios federais, que se estenderiam até o Atlântico, como espécie de isolamento nacional fronteiriço, sob a tutela da União.

A nova divisão política do Brasil, proposta pelos professores Antônio Guerra e Ignez Amélia L. Teixeira Guerra, tem, parece-nos, entre os seus méritos, o de manter com os seus limites atuais, onze estados: Rio Grande do Sul, São Paulo, Rio de Janeiro, Minas Gerais, Espírito Santo, Sergipe, Alagoas, Pernambuco, Paraíba, Rio Grande do Norte e Ceará; Territórios: Rondônia, Roraima e Amapá; e o Distrito Federal atual. Diminuem de extensão ou são fracionados os atuais estados de Santa Catarina, Paraná, Bahia, Piauí, Maranhão, Goiás, Mato Grosso, Amazonas, Pará. São 16 os novos territórios propostos: Alto Parnaíba, Alto Tapajós, Alto Xingu, Araguaia, Barreiras, Gurupi, Japurá, Javari, Juruá, Monte Alegre, Trombetas, Purus, Rio Negro e Tocantins; sugere o restabelecimento de dois ex-territórios: Ponta Grossa e Iguaçu e a eliminação do atual estado do Acre, a ser absorvida parte pelo território do Purus, parte pelo Juruá. Efetivamente, justifica-se essa última sugestão pela razão que expusemos. (GRANDE, 1965, p. 627). 
$\mathrm{Na}$ proposta de Guerra ocorre a diminuição das maiores áreas territoriais, como do Estado do Piauí, os cursos dos rios aparecem como delimitadores do surgimento de um Território Federal - Alto Parnaíba, com o surgimento do sul piauiense na proposição, ademais, os estados com pequenas extensões territoriais permanecem e a supressão do Acre é sugerida como a volta dos Territórios Federais de Ponta Porã e Iguaçu. Na proposta de Guerra, sugere um território federal no sul do Piauí.

\begin{abstract}
Com referência ao proposto território do Alto Parnaíba a sua criação com terras do extremo sul maranhense e sudoeste do Piauí proporcionaria uma benéfica ação governamental mais imediata a esse trecho de terras, distante mais de $600 \mathrm{~km}$ de Teresina e $750 \mathrm{~km}$ de São Luís. Entretanto, a localização de Carolina, sem pronunciado divisor de águas a dificultar a comunicação terrestre, permitiria absorver a área destinada a esse território pelo de Tocantins, formando assim uma unidade com superfície nada excessiva. (GRANDE, 1965, p. 629).
\end{abstract}

A área corresponde à região produtora de soja nos dois estados nordestinos, na visão do geógrafo, a ação da União seria fundamental para o desenvolvimento da parte desses territórios.

Apesar da diminuição da área territorial piauiense, apontada por Grande (1965), a ampliação do litoral do estado valida a incorporação de áreas adjacentes do Maranhão, conforme proposta de Guerra, em 1948.

\footnotetext{
No ardor da batalha esquecemos-nos de sugerir uma pequena modificação, a nosso ver importante para quem a aproveitaria: a cessão de Tutóia, com porto e terras adjacentes, do Maranhão que nem tanto dele necessita, ao Piauí, quase privado de saída para o mar. Trata-se de um pormenor já lembrado no plano Teixeira de Freitas e que já então teve carinhosa acolhida de parte a parte. (GRANDE, 1965, p.629).
}

A ampliação do litoral piauiense representa uma compensação para esse estado, em função da quase inexistência do seu pequeno litoral e, que poderia ter como complemento a área territorial maranhense, em função da ligação econômica estabelecida com o norte do Piauí.

\title{
A PROPOSIÇÃo ATUAL PARA CRIAÇÃo do ESTAdo DA GURGUEIA UMA NOVA PROPOSTA PARA PIAUÍ
}

$\mathrm{Na}$ atualidade, deve ter como pressuposto a compreensão de criação de novos estados e municípios, na relação entre espaço e o poder, ter em mente seu processo dialético de 
permanência e manutenção, construção ou surgimento de novos interesses, projeção e ampliação, permanência tinha em vista os grupos de difusos interesses.

Decorre disso uma relação estreita entre espaço e a organização política interna, que permite aos grupos do novo território uma nova centralidade do poder e o estabelecimento de relações com os outros grupos, criando novas oportunidades àquela comunidade política, tanto do ponto de vista interno, como externo Cigolini (2009). A necessidade de uma estruturação organizacional dentro do território é reconhecida também por outros autores, como Raffestin (1993, p.150) que concorda que "[...] nenhuma sociedade, por mais elementar que seja, escapa à necessidade de organizar o campo operatório de sua ação. (CIGOLINI e NOGUEIRA, 2012, p.3).

A abordagem Cigolini e Nogueira (2012), aponta para um fato importante atual, o surgimento de novos atores territoriais no sul do Estado, que impulsiona a construção de uma identidade territorial própria e diferenciada. A presença de migrantes gaúchos, sobretudo, em direção a essa região, ocorre em função da ampliação da fronteira agrícola, mas especificamente na ampliação da produção da soja.

Os movimentos emancipacionistas ocorrem na constituição do surgimento de novos municípios e na reivindicação do surgimento de novos estados, dar origem a movimentos da criação para o surgimento de novas unidades administrativas, como o Maranhão do Sul e o Gurgueia. Haesbaert (1998), analisa como ocorre esse processo como surgimento de novos atores territoriais e, ao mesmo tempo, muitas vezes, com sua anuência com as elites locais.

\footnotetext{
Por fim, politicamente, os atores da rede regional, embora sejam múltiplas suas formas de participação (ou exclusão) dos processos de decisão política, procuram de algum modo manter o controle sobre seus territórios de base local, geralmente municípios (seria interessante um mapeamento dos municípios com prefeitos sulistas ou dos processos emancipatórios comandados por sulistas fora da região $\mathrm{Sul}$ ), mas também novos estados (onde podem atuar sob a forma de alianças e coligações com grupos locais). Várias prefeituras, até mesmo no sul do Amazonas (Apuí, por exemplo), são comandadas por sulistas, e em muitas áreas eles estimulam o separatismo, de onde provém o ditado que ouvimos com certa freqüência no Nordeste: "gaúcho aonde chega quer separar". É importante lembrar que isto é fonte de conflitos, nem sempre explícitos, produto de resistências de antigas elites locais, como ocorre em Mimoso do Oeste, localidade "gaúcha" na Bahia que já possui prefixo próprio na TElEBA e, com cerca de 15 mil habitantes, a maior indústria de óleos vegetais do estado e três agências bancárias, não consegue a emancipação de Barreiras. Marilena Felinto, em reportagem na Folha de São Paulo (31.07.94) chamou de "verdadeira guerra de secessão" a tentativa dos sulistas de emanciparem a localidade de Serra dos Gaúchos, que reúne cerca de 2.000 sulistas nos cerrados do noroeste mineiro. (HAESBAERT, 1998, p. 69).
}

A constituição dos discursos além da constituição de novos atores territoriais deve ser compreendida no misto das relações existentes com os demais atores locais. As elites 
regionais têm um peso importante na constituição de novos recortes territoriais, para atenderem seu interesse econômico, político e de outras naturezas, que na maioria das vezes utilizam a população como recurso do território, Raffestin (1993), observa como as estratégias do estado, para o processo de controle de território, utilizam esse elemento como ferramenta.

Além do tamanho populacional tem-se a base territorial fundamental na constituição do controle e na formação do poder.

A área territorial e população são bases do discurso de concretização para constituição da imagem do Estado do Gurgueia e, ao mesmo tempo, para reforçar sua justificação de criação e na constituição de seu discurso pelos propositores, de acordo com os dados 2005, do Centro de Estudos e Debates do Gurgueia (CEDEG), assim, localizado no sul do Piauí (Figura 04), teria uma extensão $155.568 \mathrm{~km}^{2}$, corresponde a $61,85 \%$ da área do estado remanescente, a população é de 2.005.645.296, representado $21,46 \%$ da população estadual.

Figura 02: Proposta de Teixeira de Freitas de 1941.

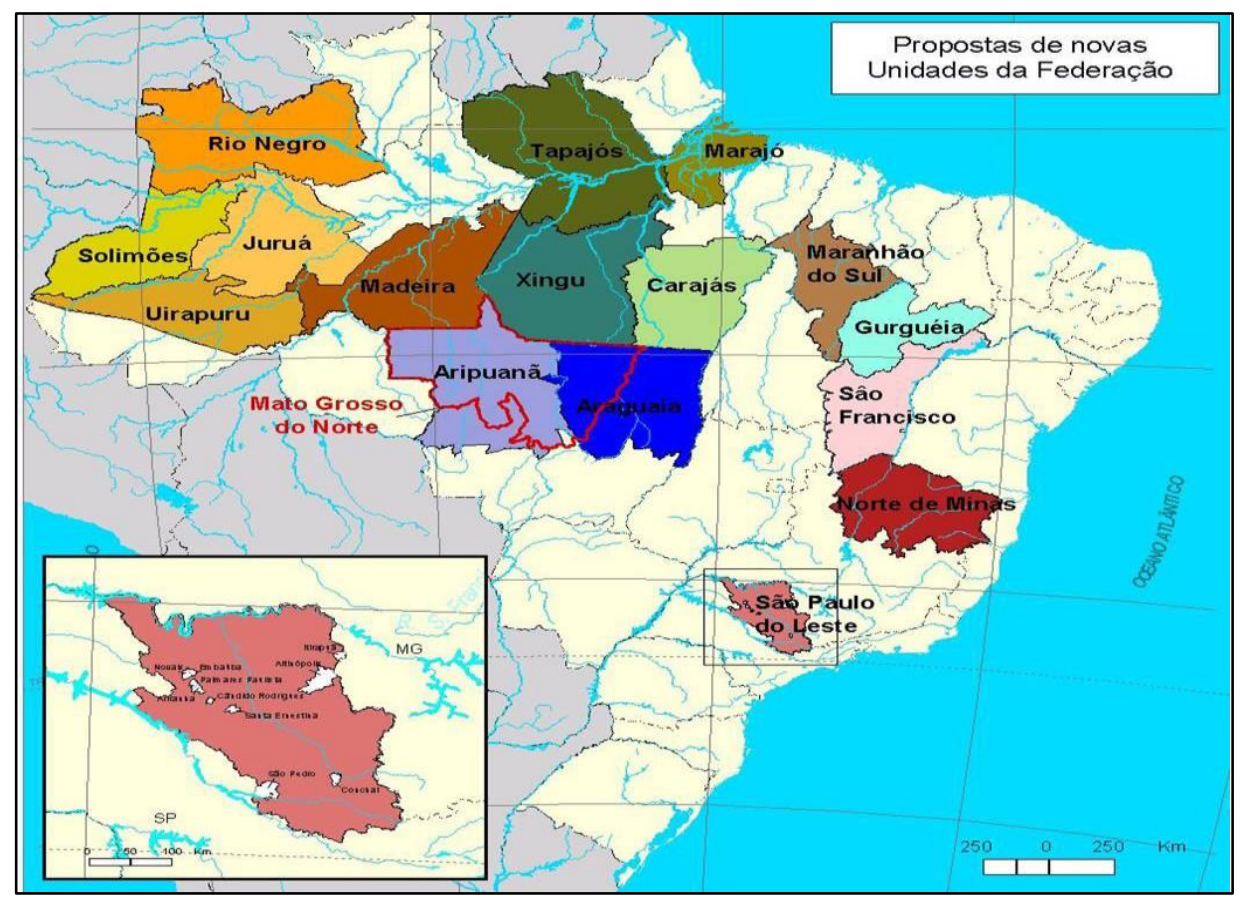

Fonte: Cigolini e Barros 2013.

As propostas observadas atualmente, com exceção do Carajás e Tapajós, que já passaram por plebiscito, segundo Cingolini e Barros (2012), que tramitam no Congresso Nacional, são representadas pela (Figura 2), todos localizados na Região Nordeste, que corresponde à região denominada atual por MAPITOBA, representada sigla de quatro 
estados, Tocantins como parte de sua constituição. Essas áreas são grandes produtoras de forte migração de gaúchos, resultado em novos discursos territoriais como na criação de novos estados.

De acordo com Soares e Façanha (s/d) existe uma cronologia referente à criação do Gurgueia, começa nos anos de 1950 e, estende-se até os anos de 2007, onde atualmente, o projeto encontra-se arquivado, observa-se abaixo o desenvolvimento dessa proposição.

\begin{abstract}
De acordo com o documento "Por que o Estado do Gurgueia?" (2005, p. 7), por volta de 1950 o então senador barrense Joaquim Pires Ferreira já chamava atenção para a criação do Estado do Piauí do Sul que seria hoje o pretendido Estado do Gurgueia. Em 1990 a questão foi levanta na Câmara Federal por Jesualdo Cavalcanti Barros, quando de seu mandato como deputado federal. Em 1977 se tivesse criado o Estado do Gurgueia, este possuiria 45 municípios dos 118 do Piauí de então. A população seria formada por cerca de 700.000 dos 2.800 .000 habitantes piauienses (Barros, 1995). Se a emancipação política do Estado do Gurgueia tivesse ocorrido no ano de 1995, Lima (1995) destaca que o novo Estado teria uma área de 150.508 $\mathrm{km}^{2}$ e seria composto por 73 municípios, sendo 46 emancipados e 16 criados pela Lei Estadual n $n^{\circ} 4.680$ de 26/01/1994 e ainda não instalados. Em 1995 o deputado federal Júlio César em seu livro "Gurgueia: um estado com vontade de nascer", defendendo a criação do Estado do Gurgueia, alega que o novo Estado seria beneficiado quanto à distribuição do Fundo de Participação do Estado, já que a lei privilegia os Estados das regiões mais pobres e tem como critério o número da população e o inverso da renda per capita, ou seja, fundamenta a ideia de que no critério compensatório e redistributivo de renda ganha mais quem tem menos e viceversa. Atualmente tramita no Congresso Nacional o Projeto de Decreto Legislativo (PDC) 439/94, de autoria do deputado federal José Francisco Paes Landim (PDT) tratando da criação do Estado do Gurgueia e dispondo da realização de um plebiscito. Em 2006 o projeto foi aperfeiçoado pelo substitutivo do deputado guadalupense Júlio César de Carvalho Lima na condição de relator. O projeto já foi aprovado em três comissões técnicas necessárias na Câmara Federal: na Comissão de Constituição, de Justiça e Redação, em 1995, e na Comissão de Finanças e Tributação em 2001. Tramita também no Senado Federal o Projeto de Decreto Legislativo $\mathrm{n}^{\circ} 55$, de 2007, apresentado pelo senador João Vicente Claudino, que dispõe sobre a realização do mesmo plebiscito. (SOARES e FAÇANHA, s/d, p.3).
\end{abstract}

Na constituição dos debates relacionados à última proposta pelo Senador Federal João Vicente Claudino (2007), de acordo com o seu Projeto de Lei $\mathrm{n}^{\circ} 55$, de 2007, é apontado os pontos principais de sua argumentação para criação do Estado O primeiro momento criar um plebiscito, que serviu como consulta para aprovação ou não dessa nova unidade, somente os municípios que o constituiriam participariam do plebiscito. As bases de princípios colocadas são: as importâncias geopolíticas na ação da interiorização das ações da União, como plano territorial, desses fatos incidem na descentralização política e desconcentração da atividade econômica, assim, o instrumento utilizado para esses objetivos seria a divisão territorial.

Outro ponto assinalado é a concentração do desenvolvimento de Teresina e o distanciamento econômico do Sul, necessária a criação de uma nova capital instalada em 
Alvorada do Gurgueia, onde irradia o desenvolvimento para as demais cidades, que constituem o sul do estado. Claudino (2007), coloca os motivos da importância do Estado e da instalação no capital ao sul.

Contrariamente, a maioria dos estados brasileiros, o Piauí foi colonizado, como visto no sertão para o litoral, o que exemplifica sua configuração fisiográfica e isolamento geográfico, econômico e cultural, com quem se vive ao longo dos anos.

Em 1852, a capital é transferida de Oeiras para o Norte do Estado, especificamente para Teresina, hoje moderna e agitada, mas cujas primeiras obras de saneamento, urbanização, eletrificação e própria aquisição do Palácio Karnac, Sede do Governo, foram fruto da economia extrativista da borracha dos sertões piauienses, que, desconhecidos na Colônia e isolados no Império, aportaram esquecidos na República, graças à incúria de sucessivos governos que concentraram as obras de infraestruturas no Norte do Estado. O abandono do Sul do Estado tem gerado uma onde de ressentimentos que desaguou naturalmente no movimento divisionista dividir para crescer - mais ainda se considerarmos o imenso potencial dos sertões e dos cerrados piauienses. (SENADO, 2007, p. 4-5).

O florescimento das atividades econômicas do Maranhão influenciou o surgimento da nova Capital Teresina, onde sua localização é facilitada pela constituição do Rio Parnaíba e a própria ligação ferroviária com estado maranhense, o enfraquecimento das oligarquias no sul do estado do Piauí enfraqueceu o papel da antiga capital Oeiras.

$\mathrm{O}$ crescimento das atividades econômicas no sul piauiense remete à necessidade da constituição de uma nova capital, baseada em torno da própria constituição histórica das atividades econômicas e do povoamento do estado, é ponto central no surgimento da unidade administrativa do Gurgueia.

Alguns questionamentos, sobre a forma de como é financeiramente o Estado, são colocados em questão em análises, que tentam apontar a autonomia financeira como em Fortes (s/d).

\footnotetext{
Embora seja verdade que o somatório dos recursos a serem repassados pelo fundo de participação dos estados para o Gurgueia e o futuro estado do Piauí será bem maior do que o valor recebido pelo atual estado, uma vez que o indicador renda per capita que será menor no Gurgueia - tem um peso inversamente proporcional ao seu valor no cálculo da quantia a receber do fundo, pode-se afirmar que haverá uma perda considerável de recursos a ser repassados pelo Estado para os municípios que poderão vir participar do Gurgueia, perda esta que não será compensada por nenhuma outra fonte de recursos constitucionais que lhes beneficiam, como é o caso do fundo de participação dos municípios, que não sofrerá alteração devido à criação de novos estados. (FORTES, s/d, p.5).
} 
Fortes (s/d) alerta que a diminuição de Fundo de Participação dos Municípios é menor para os municípios emancipados, que formam o Gurgueia, em função das receitas serem menores, produzidas pelo novo estado, ou seja, tornam-se maiores em função da própria atividade econômica do Piauí, a divisão não traria um maior repasse de verbas, mas uma diminuição.

No processo de discussão e viabilidade da criação têm pontos favoráveis, como do exdeputado Jesualdo Cavalcanti, que em sua concepção beneficiaria o próprio estado do Piauí e Novo Estado como colocado,

\begin{abstract}
Quanto ao aspecto das finanças públicas, apenas cito um dado objetivo levantado pelo Centro de Estudos e Debates do Gurgueia, para sustentar minha posição em informações consistentes: o Piauí continuaria com uma arrecadação equivalente a 98\% do ICMS atual. A diminuição do Fundo de Participação do Estado, motivada pela criação do Estado do Gurgueia, andaria em conjunto com a diminuição da responsabilidade administrativo-financeira, e o Piaú se tornaria um Estado mais enxuto e integrado. O Gurgueia ainda seria maior que doze Estados brasileiros, e o novo Piauí, maior que sete. Diante de nós há um quadro de expectativas e, mais do que isso, de possibilidades. O Tocantins, de 1989 a 2003, dobrou sua participação no PIB Nacional. Os Estados de Mato Grosso, de Mato Grosso do Sul, de Goiás e de Tocantins são bons exemplos de como a divisão territorial é benéfica, com crescimento maior que o Brasil. O que queremos é uma prosperidade equitativa. (SENADO, 2007, p.12).
\end{abstract}

Nessa concepção, a criação da unidade administrativa traz benefícios, em função das despesas administrativas, por serem menores para o Piauí, em função de diminuição da máquina pública, nesse caso, o que poderia trazer benefícios ao município do estado de origem e, sua manutenção financeira não diminuiria, dessa forma, pode ser alocado para as cidades que o formam, o estado.

Por outro lado, tem-se o Gurgueia, em que podem ser investidos financiamentos diretos nas cidades, que recebiam quase financiamento do estado, no entanto, aumentaria os investimentos diretos em função do novo formato do estado e da composição do número de municípios existentes.

Outro elemento apontado, é fundamental, no processo de criação sul do Piauí. Resultado de inúmera bancada, tem em vista que o estado seria multiplicado por dois, os interesses nordestinos. Assim, seriam beneficiados das funções dos aumentos das bancadas da Câmara e Senado Federal, repercutido teoricamente no maior número de demandas efetivas da União. 
Segundo Dias apud Valle (2008), o artificialismo dos estados em sua representação federal está diretamente ligado à desproporção parlamentar, que deveria levar em contar com maior intensidade o número de habitantes, o processo de construção de novos estados em sua concepção leva a distorção representativa no Congresso Nacional.

\section{CONCLUSÃO}

O processo de reivindicação atual da divisão do estado do Piauí não corresponde a movimento relacionado somente ao momento presente, entretanto, sua base de constituição deve ser contextualizada em função dos movimentos territoriais existentes e das forças políticas, que reivindicam uma base territorial.

Alguns elementos ainda se fazem presentes no movimento de redivisão do Piauí, como observado para criação do Estado do Gurgueia na história de sua formação territorial interiorizada, em seu processo de ocupação, demonstra a importância de uma unidade geopolítica nos sertões nordestinos, que também serve de base para surgimento do Novo Estado.

A representatividade parlamentar e captação de novos recursos são partes constituintes dos interesses das elites locais e extra locais, que compõem o mosaico de realidade, serve como base do processo de construção de uma unidade ao sul do piauiense.

\section{REFERÊNCIAS}

BACKHEUSER. Everardo. Geopolítica e Geografia Política. Revista Brasileira de Geografia, n. 1, p. 21 - 38, jan-mar. 1942.

CASTRO, Iná Elias de. Solidariedade Territorial e Representação de Novas Questões para o Pacto Federativo Nacional. Revista Território, n. 1(2), p.33 - 42,1997.

CENTRO DE ESTUDOS E DEBATES DO GURGUEIA - CEDEG. Disponível em < www.gurgueia.org.br/inscricoes.asp> Acesso em 19 fevereiro 2014.

CIGOLINI, Adilar A.; NOGUEIRA, João Francisco M. Territorialização e a Criação de Novos Estados no Brasil. In: XII Colóquio Internacional de Geocrítica, 2012, Bogotá: Trabalhos. Bogotá: Unal, 2013, p. 1-7.

EGLER, Eugênia Gonçalves. Distribuição da População no Estado do Piauí em 1940. Revista Brasileira de Geografia, n. 4, p. 486 - 495, out-dez. 1952. 
FLEMING, Thiers. Nova Divisão Territorial do Brasil. Revista Brasileira de Geografia, n.2, p. 250 - 255, abr. 1940.

FORTES, Raimundo Leôncio Ferraz. O Estado do Gurgueia, Desenvolvimento e Sustentabilidade Tributária e Financeira (s/d). Disponível em < www.coreconpi.org.br/...es/download/5/O_Estado_do...Acesso em 19 fevereiro 2014.

FREITAS, M. A. Teixeira. A Redivisão Política do Brasil. Revista Brasileira de Geografia, n.3. p.533,549, jul.- Set. 1941.

GRANDE. J. C. Proposição de uma nova divisão política do Brasil. Revista Brasileira de Geografia, n. 4. p.625, 640, out-dez. 1965.

HAESBAERT, Rogério. A Noção de Rede Regional: Reflexões a Partir da Migração "Gaúcha no Brasil”. Revista Território, nº 4. p. 55, 71, jan./jun. 1998.

MAGNOLI, Demétrio. O Estado em busca do seu Território. Terra Brasilis, n. 4.5, 2003.

MARTINS, H. T. A fragmentação do território brasileiro: a criação de novos estados no Brasil. Caderno CRH, Salvador, n. ${ }^{\circ}$ 35, p. 263-288, jul./dez. 2001.

NOGUEIRA, Ricardo José Batista. Amazonas a divisão da "monstruosidade geográfica". Manaus: Fapeam. 2007.

RAFFESTIN, C. Por uma geografia do poder. São Paulo: Ática, 1993.

SENADO FEDERAL. Projeto de decreto Legislativo $\mathbf{N}^{\circ}$ 55, de 2007. Brasília: 2007.

Disponível em < http://www.senado.gov.br/atividade/materia/getPDF.asp?t=46866\&tp=1>. Acesso em 19 fevereiro 2014.

SENADO FEDERAL. Estado do Gurgueia: Sonho e realidade. Brasília 2007 Disponível em < www.correiodoestado.com.br/...sonho-e-realidade_77642> Acesso em 19 fevereiro 2014.

SOARES, Edivan C.; FAÇANHA, Antônio C.. "A Criação do Estado do Gurgueia: Impactos no "Novo" Piauí (s/d). Disponível em < portalgurgueia.com.br/index.html> Acesso em 19 fevereiro 2014.

VALLE, Pedro. A Criação de Novos Estados: verdade e mito. Brasília: Editora de Brasília LTDA, 2008.

VIANA, João Segadas. Divisão Territorial do Brasil. Revista Brasileira de Geografia, n.3. p.372,406, jul. 1940.

Recebido em Dezembro de 2015

Aprovado em Abril de 2016

Publicado em Junho de 2016 